\title{
STUDENT EXPERIENCES OF MICROTEACHING: PROMOTING REPRODUCTIVE OR INNOVATIVE LEARNING?
}

\author{
M. N. Davids \\ College of Education \\ University of South Africa \\ Pretoria, South Africa \\ e-mail: Davidsnoor56@gmail.com
}

\section{ABSTRACT}

Work-integrated learning (WIL) provides a framework for pre-service student teachers to prepare for professional practice. According to the Department of Higher Education's policy on the Minimum requirements for Teacher Education Qualification (2011), student teachers are to acquire tacit knowledge and skills which are essential components of learning to teach. Practical learning is a form of learning 'in and from' practice. Microteaching is often adopted as a strategy to initiate pre-service students into the practical world of teaching. Learning 'in practice' involves teaching in authentic and simulated environments. Informed by the research question: "what are first-year students learning experiences in a microteaching programme?', this article evaluates pre-service students' experiences of a microteaching programme. First year students' evaluation forms, document analysis and participant observation were used to provide data for this study. Student evaluation forms were analysed and coded on the basis of common usage of expressions, phrases and ideas. Patterns of meaning were identified and extracted from the data. Goffman's notion of 'frames' was used as analytical lens to illuminate student involvement. This article argues that multiple interactive frames that operate during microteaching often let the student diminish as main focus which compromises the objective of microteaching: to provide pre-service students learning opportunities in a simulated and unthreatening environment. Despite the lack of explicit objectives and contradictory student experiences, this article further argues that microteaching presents students with numerous opportunities for learning. Given the close link between microteaching and the all-pervasive $21^{\text {st }}$ century technological teaching environment, microteaching is poised for a new wave of popularity. To achieve the objectives of a microteaching programme, it should intractably be student-centered. The student should be maintained as main focus and beneficiary. To this end, recommendations are made.

Key words: frame analysis, microteaching, pre-service teachers, teacher education

\section{INTRODUCTION}

After twenty one years of democratic governance and educational reform in South Africa, teacher education institutions are constantly evaluating their initial teacher education 
programmes in terms of its fitness for purpose. A nation's education system and in particular, its teacher education programme becomes crucial in determining the quality of education imparted to learners. Teacher education is globally expected to be responsive to the needs of the economy and society. Appropriate competencies and tacit knowledge are to be developed to maintain an edge in an increasingly competitive global economy. As an integral part of the teacher education qualification, the 'teaching practicum module', provides the context for work-integrated learning to take place. During the teaching practice session, students are exposed to learning 'in' and 'from' practice. In preparation for the actual teaching practice experience, microteaching is often adopted as a strategy to create a safe passage for students to be inducted into training. Microteaching can potentially contribute towards developing competencies and skills required to maintain and improve the quality of educational practice of students. Microteaching is often employed without thorough planning and preparation. Before the implementation of a microteaching programme, its objectives and intended outcomes are to be specified. These considerations should be critically assessed in the context of its theoretical and methodological options. This article critically investigates the results of a microteaching programme using students’ experiences as data.

The Norms and Standards for Educators (NSE) policy of 2011 (DoE 2011) focuses on the seven roles of the teacher and the required competencies that teachers are expected to demonstrate. In brief, the seven roles encompass proficiency in the following areas: subject or phase, teaching and learning, assessment, curriculum development, a leader and administrator, lifelong scholar, citizen and pastoral role (DoE 2006, 5). According to policy, the teaching practicum periods are described as work-based experiences and on-site induction into situated contexts of practice. The practicum constitutes 120 credit points out of a total of 480 (25\%) which the student requires to obtain the B.Ed. degree (Reddy et al. 2008, 144). Given the challenges facing teacher education, higher education institutions have mainly retained known practices of teacher training and in particular the teaching practice component (Reddy et al. 2008, 144). Robinson (2003) asserts that teacher educators intimated that they rarely consulted policy documents when they plan their programmes and often make cosmetic changes to suit registration requirements of national authorities. Often programmes are implemented based on known practices and past experiences without reconsideration of existing conditions or policy changes.

Historically, microteaching has been part of teacher education in South Africa for many decades. In the post-apartheid period it is still being employed in a variety of ways. In a multisite study where microteaching was used, an observation was made that microteaching 
experiences seldom lead to goal integration as they are devoid of 'real-life' experiences and often lack sufficient complexity (Reddy et al. 2008, 158). There are various models of microteaching. Microteaching refers to the common practice of having students in educational method courses 'teach' a lesson to their peers or learners in order to gain experience with lesson planning and delivery (Bell 2007, 24). Microteaching has generally been found to present effective ways of helping pre-service teachers learn about, and reflect upon teaching practices (Bell 2007, 24). There has generally been a positive response from students and lecturers towards microteaching, and perhaps because of it, researchers have not sufficiently examined microteaching critically as a conscious strategy for pre-service preparation. Given the role of teacher education institutions, this article reviews the educational objectives of a particular microteaching programme in light of students' experiences. There is arguably no clarity between practices of microteaching and its theoretical and philosophical underpinnings. On a global level, microteaching has been adopted by various institutions to address local needs and practices. Given the increasing globalization of social and economic systems in the $21^{\text {st }}$ century, microteaching may be facing a new wave of popularity. By adopting an approach that is student-centered, microteaching offers many practical options to address specific needs and requirements of students. Technology provides an ideal 'mirror image' which become available to the student to assist in self-reflective activities that may enhance future personal growth and development. The use of technology in microteaching will encourage students to take responsibility for their own development, instead of them replicating existing ideas and practices (DoBE 2011, 1).

On a local level, there are limited studies on the synergy between microteaching and education policy resulting in a questioning of its educational objectives and its relation to current policy. Notwithstanding polemical debates concerning microteaching, studies reported positive outcomes (Higgins and Nicholl 2003, 220). Presumably, the use of microteaching as an experimental design presupposes a notion of a predefined 'teacher'. This assumption may be construed as essentialist and deterministic which is problematic given the diversity of the South African classroom. Viewed as a positivistic methodology, microteaching emphasizes micro-level experimentation in an environment that eliminates the complexity of the external world (Schoeman and Mabunda 2012, 242). But, paradoxically, there may be deep learning moments embedded in a micro-level analysis. Without discarding the positive studies on microteaching as a positivistic methodology, the South African context would find relevance in a critical constructivist approach which is based on the belief that no single approach is sufficient for developing a valid understanding of a phenomenon (Angen 2000, 378-395). 
In this article a microteaching programme is evaluated in light of the experiences of first-year students who are being prepared for their first teaching practice session. The research question that this study intends to answer is: 'what are students' learning experiences of a microteaching session?'. Goffman's notion of 'frames' (Bell 2007, 26) was used as analytical lens to understand student experiences in the programme. This article argues that microteaching presents many learning opportunities to pre-service students but the focus of the activity often veered away from them. Experiences of students also caution that a lack of clear objectives compromises the effectiveness of the programme and may produce inconclusive results. Based on the findings, recommendations for future practice are suggested.

After this introduction, the article unfolds as follows: a brief exposition of the context of this study, reference to microteaching from a historical viewpoint and an explanatory note of the theoretical lens employed, a brief note on methodology, presentation and discussion of the main themes as findings followed by my conclusion that reviews the findings critically, and make recommendations to enhance microteaching as a useful simulation exercise in teacher education.

\section{CONTEXT AND BACKGROUND OF THIS STUDY}

The context of this study is a South African merged university of technology's faculty of education. The faculty of education constituted a number of former colleges of education. After ten years, transformation challenges are still being encountered at the level of structure and practice as the core identities of former colleges tend to persist. The microteaching session was designed in response to an institutional audit conducted by the Council on Higher Education (CHE). The audit reported that the largest first-year student dropout rate in the faculty happens normally after students have been to the schools for practice teaching in their first year. Microteaching was employed as strategy to address this concern: an acknowledgement that many students are ill-prepared for teaching practice. The microteaching programme was organized two weeks before students went out to do their first teaching practice session for the year. Two weeks of the academic calendar are reserved for a teaching practice workshop session. During the first week of the workshop, all intermediate and senior phase (ISP) students (first to fourth year) were exposed to informational sessions associated with teaching and professional practice. These sessions consisted of talks by guest speakers, subject-related issues on lesson plans and useful talks on the school as an institution and teaching practice. The second week was dedicated to prepare first-year students for the 
microteaching session. The first two days were used for students and lecturers' consultation pertaining to subject-teaching and lesson plans. One day was used to teach students to design flashcards and posters. The last two days of the week were used for actual microteaching sessions.

Learners from a neighbouring primary school were invited to participate in the microteaching sessions as guinea pigs. The programme was designed in collaboration with a liaison teacher who assisted and participated in this programme the previous year. The following document provides an evaluation of the previous year's programme. The following three aspects emerged from the report:

1 The programme was pioneered the previous year and 'students felt confident going into schools'. There were relatively few complaints from schools about students in comparison to the previous years and the 'dropout rate that was of concern in the past was resolved'.

2 The liaison teacher from the invited primary school submitted a report noting that lessons were crammed and that students often repeated their lessons because they had nothing new to teach. Too many teaching aids often of a poor quality were used. She recommended that when students are paired they 'don't teach with someone else whose teaching aids and style differ from their own'.

3 These recommendations were incorporated in the design of the new programme. It was noted that: students were not always preparing for the grade that they were supposed to be teaching; closer contact with the primary school was necessary to find out what 'the school expects'. The liaison teacher's involvement in the preparation would be increased by being present during the three days prior to the microteaching session and that she will act as 'an additional evaluator' of the lessons during the actual microteaching.

In general terms, the objective of the microteaching intervention was to prepare pre-service student teachers for the teaching practice session which was imminent. After the microteaching sessions, students would go into the classroom better prepared. I will return to this issue to review the outcomes of the programme. Given the context and background of this microteaching programme, the following section locates the study in extant literature. Goffman's 'frame analysis' provides the theoretical lens to interpret the data and will be explained below. 


\section{RE-EMERGENCE OF MICROTEACHING IN TEACHER EDUCATION}

Microteaching dates back to the early 1960s (Higgins and Nicholl 2003, 220). At Stanford University, microteaching was perceived in a cyclic way, involving the following steps: plan, teach, observe, re-plan, re-teach and re-observe (Brown 1975, 15). The University of Ulster amended this model to a three-stage model: plan, teach and observe. Quinn (2000) suggests that microteaching is a cycle of events which consists of the performance of micro-skills recorded on videotape and played back for evaluation and improved practice. Jacques (2000) argues that video recording and play-back of skills have benefits in teaching. Behaviours and events in the video are highlighted for the groups which provide points for discussion. Minton (1997) argues that microteaching provides a platform for practice without fear of failure. Microteaching has been recommended as a means to reduce anxiety among student teachers (Nwanekezi et al. 2011, 41).

Student reflections on their teaching practices have been enhanced by video recording play-backs. Some studies reported that pre-service teachers receive limited feedback because of time constraints: they have limited opportunities to reflect on their practice (Du Plessis et al. 2011, 34). In this regard, the video-based methodology may be used to reflect on realistic classroom situations that give teachers the opportunity to share experiences (Rowley and Hart 1996; Friel and Carboni 2000). Video-based pedagogy of learning has not been analysed to support claims that it is a successful and proven methodology. On the contrary, the use of videos for self-evaluation as described in Baker (2000) is minimal at best. Notwithstanding the popularity of microteaching as a means to help pre-service teachers learn and reflect upon their teaching, Bell, $(2007,24)$ claims that there is still not clarity about defining what microteaching means. Bell’s (2007) analysis of tapes and questionnaires reveals that microteaching resembles 'performance' or 'classroom task' to a much greater extent than it does 'teaching'.

In a post-apartheid classroom, learning should ideally be informed by contextual knowledge of which the socio-economic conditions of the learner should be an integral part. Other than that, teacher education programmes are expected to integrate a number of learning types: disciplinary, pedagogical, practical, fundamental and situational (DoHE 2011, 11). Therefore, the decision to use microteaching in teacher education should be a calculated one. The selection of microteaching as part of teacher education should be in line with the learning objectives of teacher education. Its outcomes should be openly defined and its benefits should ideally be integrated into a continuous programme as part of the initial teacher education programme. 
Microteaching may potentially deal with aspects of all these learning types, but it should be clear as to what specific learning type it intends to address. Notwithstanding all the resources invested in initial teacher education programmes, the Higher Education monitor (2010) noted that many students replicate their own set of schooling experiences in their work-based learning. Such replication indicates that teacher education programmes do not focus on developing reflective and critical students. Self-reflection and a critical awareness are essential characteristics to develop during teaching practice. The use of microteaching in pre-service teacher education should be a critical activity and not a replication of familiar practices. It should provide opportunities for students to avoid the master-apprenticeship model of teacher development which emphasizes the development of teaching competencies through re-modeling the practices of expert teachers (Robinson 2014, 117). Strategically, intervention initiatives should place student teachers at the centre of their course objectives and enable them to take substantial responsibility for their own development, instead of them replicating, that is mechanically repeating, existing ideas and practices (DoBE 2011, 1). Needless to say, the microteaching study under investigation was not tightly guided by specifically defined pedagogical objectives: its outcomes were not defined, neither was there any reference to the learning types that student teachers had to pursue or achieve. There was also no time allocated for self-reflective action: the conscious integration of potential learning moments into useful knowledge and skills for future growth.

\section{THEORETICAL LENS}

Bell (2007) reviews performance theory in teacher education. He uses this theory to explain microteaching as a performance rather than teaching. Bell (2007) borrows from Erving Goffman's (1959) conception of how performance is constructed but is not the performance itself. In the context of this study, the focus is on how various participants draw value from their involvement. Goffman uses the notion of 'frames' which are the participants' culturallydetermined definitions of an interaction which helps to guide and shape behavior (Bell 2007, 26). Goffman recognizes the instability and multiplicity of frames and the way in which they are transformed into action. His question: 'What is it that's going on here' (when microteaching actually takes place) assumes that frames are co-constructed through interaction, emerging locally and shifting from moment to moment (Bell 2007, 26). Any attempt to describe them should, necessarily, be recognized as partial. In a microteaching context, the multiplicity of actors makes understanding multiple frames-in-action a complex issue. 
An application of Goffman's frame analysis is appropriate in this study because a number of frames are identifiable individually and interactively. In this study, participants' observation and documents to assess the number of participants were relied on. The identified frames were: the student assuming the role of the practicing teacher, lecturers assuming the role of expert advisors, primary school learners participating as actual learners in a simulated classroom, peers of students and the liaison teachers from the primary school. Goffman's theory explains people's interaction with, and understanding of, their environment through the use of existing mental frames of reference. As an individual moves through life, he/she interacts with other people. They learn patterns of behaviour in response to different situations and settings. Frames are formed and aid the individual in responding to, and understanding, situations. The main components in frames are certain words, actions or phases that provide cues to guide behavior and understanding in those situations (Woods 2007, 3). These frames are the mental foundations that people develop and utilize throughout their lives (Woods 2007, 3). In this study, influences of various frames on the evaluation of a learning activity will be made. Needless to say, these will assist in understanding the complexity of evaluation and answering the main research question: 'what are first-year students learning experiences in a microteaching programme?’.

\section{RESEARCH PROJECT AND METHODOLOGY}

The context of this microteaching exercise is a first-year 'teaching practice preparation' workshop. The faculty of education allocated two weeks in which the general education and training band (GET) could prepare students for the first teaching practice session of the year. The first session is normally scheduled to take place during April.

\section{METHODOLOGY}

A qualitative approach is appropriate to understanding students' learning experiences and to explain an argument using evidence from data and literature (Henning et al. 2004, 3). Data collecting techniques employed in this study were student evaluations, documents analysis and participant observation. Ethical clearance for the project was applied for and granted. Forty-two (42) student evaluation forms were completed after the microteaching sessions. Documentary evidence is based on programme material and a report. Evaluation forms were structured around four main areas of engagement mentioned below. The forms provided openended space for personal reflections. The participant observer recorded experiences as fieldnotes. The previous microteaching report was used to provide context and background to the 
study. The teaching practice workshop programme provided a comprehensive picture of the structure and activities. Student evaluations were analysed in terms of the following issues:

- $\quad$ Assistance received from lecturers

- What students liked about the microteaching exercise

- What they disliked about it

- What they learnt, suggested and recommended for the future.

Student responses were plotted on a spreadsheet and placed under designated categories which were coded. These categories were subjected to content analysis and grouped on the basis of common usage of words, expressions and ideas that constitute identifiable themes. Experiences of students were constructed as four main themes which are presented as findings.

\section{DISCUSSION ON FINDINGS}

In this section, the main experiences are grouped under four headings, each supported by extracts of data. Employing Goffman's (1959) notion of frames in this study, a number of different frames were identified singularly and interactively. Because microteaching should be focused on the student and his/her personal development, this analysis focuses on student experiences as the main frame of microteaching. As referenced earlier, the programme under analysis was not informed by clearly defined outcomes neither was any definitive reference made to specific competencies, skills or learning types. Student experiences however, would be a good indicator of learning and value of the programme as part of an initial teacher education initiative.

\section{LEARNING FROM LECTURERS}

The microteaching context provides many opportunities for personal learning and reflective action. Most students responded positively in terms of the guidance and advice that they received during this session. Generally, there prevailed a feeling that lecturers shared their experiences and knowledge with the students. Students noted: 'lecturers were helpful and provided advice'. 'Lecturers on the whole assisted with lesson plans, how to introduce and conclude a lesson.' These activities are task-oriented and the advice was about doing things better. Some of the students projected a passive role while others expressed a more critical and questioning approach (Rowley and Hart 1996). Sometimes lecturers appeared to have 
been contradictory. 'Some assisted and others made me confused'; while another commented that, '... certain were helpful and others a waste of time'. Students adopted critical frames in which they saw themselves as active thinkers. Some were critical of the programme and stated that it should not be implemented for first-years, '... microteaching should not take place in the first-year because it is too soon'. What is implied here is that first year student may not possess enough content knowledge to venture into classroom teaching.

Students and lecturers approached the microteaching classroom without clear expectations. They created their personal objectives based on past experiences (Goffman 1959). Some students appreciated the feedback sessions while others were skeptical about the comments. Multiple possibilities that are presented for comment emanated from multiple frames that interacted at the level of practice. Student experiences of helpfulness or vulnerability presented some of the contradictory experiences. A successful microteaching programme should specify the pedagogical objectives before the exercise is implemented. If an objective of microteaching was to prepare and expose students to the realities of workintegrated learning, then the experiences of the students provide some opportunity for reflective action. Students were confronted with real-life situations which kick-started their reflective processes. Based on the premise that teacher education is a life-long process, students have been exposed to different views by lecturers. They were nurtured into making their own decisions and choices - essential learning moments which became part of their teacher training and education.

While students gain much from the participating lecturers, they would have gained more if a common and shared set of objectives were agreed upon before the implementation of the programme. Contradictions created possibilities for reflexivity which might initiate critical and self-directed learning. Self-reflective action becomes an essential component of a successful microteaching cycle and should be incorporated in the planning stages.

\section{LEARNING ABOUT CONTENT KNOWLEDGE AND PERFORMANCE}

In response to the question: what students liked about the microteaching experiment, cognitive and affective views were expressed. These responses imply that meaningful interaction took place during the activity. Students were appreciative of feedback they received on content and pedagogical issues. Concerning 'how' and 'what' to teach and do lesson plans, the following are some responses: 'I know what I have to do when teaching'; and 'lecturers gave advice and gave content examples on how to teach science, mathematics and art'; 'We learnt how to use teaching aids'. Some students framed their experiences from 
the perspectives of the lecturers who were viewed as experts in the field. When lecturers engage students, they assume that the main frame projects their experiences as valuable. Students responded that '... I learnt how to handle the learners'; '... I learnt how to manage my class'.

Learning how to teach and what to teach are inseparable aspects in teacher education. As novices, these students are exposed to learning about teaching which enriches their experiences. These claims of first-year students are totalizing statements which show that they do not display a deep understanding of teaching. This notwithstanding, students reported that '... I learnt to be confident and use my voice’; 'we learnt how to bring out our personality into practice'; 'I learnt about myself and how to conduct myself ...'. These positive comments are indicative of the meaningful exposure that students experienced which can become useful as future frames of references. Students' experiences were overwhelmingly focused on 'how' which emphasizes the performative aspect of the microteaching activity. Once again the value of the microteaching approach shows its usefulness in developing competencies and skills and if applied conscientiously, its resourcefulness could be utilized appropriately. Performative practices focus on the 'how' about teaching, but the 'what' should not be underemphasized when implementing a microteaching programme. When microteaching is not informed by clear objectives and pedagogy it stands the risk of reproducing existing practices instead of allowing students to become involved in self-directed and life-long learning. During the microteaching session students integrated performance and teaching experiences. Applying their experiences to frame analysis, students would be learning about teaching as performance and teaching as deep learning. There should be an explicit objective to enhance students' content knowledge as well as didactical skills and competencies. To achieve these outcomes, all stakeholders should have a common approach, informed by a sound reason and based on knowledge of the students' needs.

Evidence shows that the microteaching programmes yield both 'performance' and ‘teaching’ practices (Bell 2007, 24). Identified learning objectives could provide an overlaid structure and attainment of specific outcomes. Microteaching seems to have the potential to introduce best practices as well as instilling critical thinking which may emerge when contradictions are experiences.

\section{LEARNING THROUGH EMOTIONAL EXPERIENCES}

Students were often disturbed by certain experiences during the microteaching programme. Confusion elicited emotional responses which shifted the frames to other participants such as 
'learners', and 'lecturers'. Some students expressed discontent that some group members were not presenting lessons which was regarded as unfair. A greater sense of 'injustice' was signaled when some students absented themselves when they had to give lessons. Some partners deserted them because they were 'incompatible'. Based on the previous year's microteaching report, the liaison teacher suggested that students work with those with a similar 'teaching style'.

Emotional frames are fragile and potentially destabilizing: they intersect with the cognitive and performative functions of teaching. Working in pairs involves collective planning and implementing complicated decision-making. Not only were students expected to learn to teach but they had to account for the learning of the learners to provided evidence of successful teaching. The active involvement of liaison teachers (from primary school) granted them prominence in the programme and added another dimension to the microteaching experience. Liaison teachers not only create extra frames on the scene, but they become part of a programme not designed for them. The objective of the microteaching programme was further complicated when the participating schools' 'expectations' were super-imposed as a larger frame over the programme. The multiple interactive frames operating in the context of the microteaching experiment produced emotions of confusion and alienation which influenced students’ experiences negatively.

An observation could be made that students' emotions were largely neglected as their involvement was not negotiated. Many were disillusioned by their allocated partners who were often reported as unco-operative and absent. 'We were forced to be with a partner against our will', one student claimed. Evidently, lack of a main frame/focus contributed towards the negative emotional experiences of the students (Nwanekezi et al. 2011, 41). The prominence of these emotional responses of students highlights an important dimension in the microteaching experiment which should inform future planning. A clearly define objective and an acknowledgement that the students' growth and development are central to the microteaching programme, may minimize the negative emotions which erode the pedagogical value of the exercise. The reduction of negative emotions during the microteaching programme may be facilitated by a common purpose, shared by all participants.

\section{LEARNING ABOUT ORGANIZATION AND PLANNING}

Many students' critiqued the organizational quality of the programme. First, the question of time allocation and management caused disconcertedness. Some students claimed that there was not enough time to prepare eight (8) lessons. Students had to prepare two lessons for each 
of the four allocated subjects which they claimed were too many. Students claimed that too much time was allocated for making teaching aids. Some mentioned that they wasted time doing the flashcards. Microteaching allows for lessons to be of shorter length. The adoption of a 30 to 45 minute period should not be taken as norm for the duration of a lesson.

Some lecturers caused confusion. The following are some responses: 'They had their own ways which is confusing'; '... it caused conflict and we did not know what to do'; 'some lecturers were not prepared to help us ... I was embarrassed'. 'Some lecturers did not prepare for their sessions ...'.

Involving participants in a focused programme such as microteaching, demands skillful and meticulous planning. Without a common objective and participation of others in the planning stages, may result in a lack of commitment. Given the negative responses to lecturers' participation, the question arises whether a common approach had been agreed upon beforehand or whether lecturers' involvement in microteaching was based on their subjective understanding of the experiment. Once again, a frame analysis of participants assists in understanding what actually happens during microteaching. Given the common objective that the student should be the main beneficiary of the microteaching programme, the planning and organization should be participatory with due consideration given to the role and functions of participatory frames. The recognition of the student as the main frame of microteaching would enhance its pedagogical value and provide tangible outcomes of the programme in relation to its objectives.

\section{CONCLUSION}

The argument was posited that microteaching may be on the threshold of a new wave of popularity given the pervasiveness of technology in the $21^{\text {st }}$ century teaching environment. Because microteaching has always been used as part of teacher training, its outcomes are often taken for granted. It is often employed without careful planning and implementation. This study investigated the experiences of students who participated in microteaching programme and concludes that, despite lack of defined pedagogical objectives, some positive learning were recorded. The argument is further developed that for microteaching to become an effective intervention in teacher education, it should be resolutely student-centered and self-reflexive: the student as main frame (Goffman 1959). In response to the research question: 'what were first year students' experiences of a microteaching programme?', this article concludes that student experiences were of a varied nature covering general pedagogical issues such as lesson plans and reflective action; performative and deep subject 
learning, learning about the affective and learning about planning and organization.

Teaching practice provides opportunities for students to learn 'in' and 'from' practice and during the microteaching programme they are initiated into professional knowledge and pedagogy. The microteaching experience provides a safe entry into the classroom because students would have acquired some self-knowledge and confidence about what awaits them in the future. As part of a holistic pre-service training programme, there seems to be sufficient evidence that microteaching made some positive contributions to the development of the first year students.

While there may be some justification for the use of microteaching in teacher education, it should be mentioned that it requires careful planning and implementation. The use of the frame analysis indicates that microteaching consists of multiple interactive frames that involve cognitive and emotional experiences which present possibilities for reflection. The argument, however, is made that, if microteaching is not constructed with clear educational objectives aligned with students' identified needs, it may be an exercise in futility with all the advantages of inherent economy resources of little value.

If Goffman's concept of frames is applied to microteaching and the question: 'what is it that is going on here', is posed, then microteaching has both positive and negative elements. Goffman's frame analysis identifies the dynamic nature of the microteaching exercise. In the context of this study, multiple frames such as the students, learners, lecturers (supervisors), liaison teachers and the imposed external frame from the school, provide a lucid picture of a complex process of social interaction. These frames, according to Bell $(2007,26)$, are culturally determined definitions of an interaction which helps guide and shape behavior. Frames are co-constructed through interaction, emerging locally and shifting from moment to moment. Any attempt to describe them should necessarily be recognized as partial. In a microteaching context, the multiplicity of actors makes its understanding a complex issue. Oft-repeated concerns of researchers are that the educational value of microteaching has not sufficiently been proven. In the design of a microteaching intervention, the objective of the exercise, which is the growth and development of students, should be kept as the main frame. Sub-frames should be acknowledged for their supportive roles.

Microteaching should be used in a planned and consistent way. There should be alignment between educational objectives and intended outcomes but not in a teleological way. All participants should be prepared and their roles clarified. Time for reflection should be part of the planning process. In the context of this study, a lack of reflective sessions impacted on its pedagogical value. The lessons were full-length: the comments were that 
lessons were too long and students ran out of knowledge. A typical microteaching cycle of planning - teaching - feedback - replanning (Brown 1975, 15) should guide the process. From a practical perspective, microteaching can be employed as a 'surveillance technique' to identify needs of students that require post-microteaching intervention. Ideally, there should be an awareness of the resources needed in the training process and full realization of the benefits to students.

A microteaching intervention programme should be designed along critical constructivist objectives despite the use of a seemingly overt positivistic experimental design. As an exposure and exploratory technique, it can be argued that microteaching may become a meaningful activity to move away from habitual replication of known teaching practices to reflective critical learning. While the competencies and skills to be developed in teacher education programmes should become the focus of a microteaching intervention, a critical constructivist approach that allows for a flexible use of methods and techniques, should be favoured over an approach that is based on a narrow predetermined and reductionist notion of a teacher. An ostensibly positivistic approach which microteaching may be construed to be, does not presuppose a reproduction of existing pedagogical practices. Paradoxically, microteaching has the potential to provide a pedagogical framework to develop critical and creative learning. An effective programme recognizes the need for best practices and tacit knowledge that students need to integrate as they embark on their journey as lifelong learners and teachers. Maintaining the student as main frame and focusing on learning, a microteaching programme should recognize that both existing and new knowledge should become clearly identifiable outcomes that should enhance student development and growth.

\section{REFERENCES}

Angen, M. J. 2000. Evaluating interpretive inquiry: Reviewing the validity debate and opening the dialogue. Qualitative Health Research 10: 378-395.

Bell, N. D. 2007 Microteaching: What is it that is going on here? Linguistics and Education 18: 2440.

Baker, E. A. 2000. Case-based learning theory: Implications for software design. Journal of Technology and Teacher Education 8(2): 85-95.

Brown, G. 1975. Microteaching a programme of teaching skills. Metheun, London.

Cape Peninsula University of Technology. 2013. Draft Panel Report GET: Intermediate and Senior phase. Cape Peninsula University of Technology.

Council on Higher Education. 2010. CHE report on the national review of academic and professional program in education. CHE Monitor No 11, August 2010. CHE Auckland Park 2092, South Africa.

Department of Education. 2006. The National Policy Framework for teacher Education and Development in South Africa. Pretoria. 
Department of Basic Education. 2011. Integrated strategic planning framework for teacher education and development in South Africa: 2011-2025. Pretoria.

Department of Higher Education and Training. 2011. Minimum requirements for teacher education qualifications. Government printers Pretoria.

DoBE see Department of Basic Education.

DoE see Department of Education.

Du Plessis, E. C., P. Marais and A. van Schalkwyk. 2011. The role of lecturers as mentors in the assessment of student teachers. Progressio 33(1): 23-42.

Goffman, E. 1959. The presentation of self in everyday life. New York: Doubleday.

Henning, E., W. van Rensburg and B. Smit. 2004. Finding your way in qualitative research. Van Schaik, Pretoria.

Higgins, A. and H. Nicholl. 2003. The experiences of lecturers and students in the use of microteaching as a teaching strategy. Nurse Education in Practice 3: 220-227.

Jacques, D. 2000. Learning in groups $-a$ handbook for improving group work. $3^{\text {rd }}$ Edition. Kogan Page, London.

Schoeman, S. and P. L. Mabunda. 2012. Teaching practice and the personal and socio-professional development of prospective teachers. South African Journal of Education 32: 240-254.

Minton, D. 1997. Teaching skills in further and adult education. MacMillan Press Ltd, London.

Nwanekezi, A. U., N. J. Okoli and S. A. Mezieobi. 2011. Journal of Emerging Trends in Educational Research and Policy Studies 2(1): 41-46.

Quinn, F. 2000. Principles and practices of nurse education. Stanley Thornes, Cheltenham.

Reddy, C., H. Menkveld and E. Bitzer. 2008. The practicum in pre-service teacher education: A survey of institutional practices. South African Review of Education 14(1-2): 143-164.

Robinson, M. 2003.Teacher education policy in South Africa: the voice of teacher educators. Journal of Education for Teaching 29(1): 19-34.

Robinson, M. 2014. Selecting teaching practice schools across social contexts: Conceptual and policy challenges from South Africa. Journal of Education for Teaching 40(2): 114-127. http://dx.doi.org/10.1080/02607476.2013.869970 (accessed 22 May 2014).

Singh, S. K. 2012. The changing nature of assessment in teacher education. Journal for Social Science 33(1): 115-124.

Woods, J. 2007. 'A hangout with a view' rural strip clubs: An ethnographic exploration. UW-L Journal of Undergraduate Research $X$. 